Z. Klin. Chem. Klin. Biochem.

10. Jg. 1972 , S. $512-515$

\title{
Wirkung von Heparin in vitro auf die Reninaktivität im Plasma1)
}

\author{
Von H. Lindstaedt²), Hannelore. Schmidt, H. Kaulhausen ${ }^{3}$ ) 'und H. Breuer \\ Aus dem Institut für Klinische Biocbemie und Klinische Chemie der Universität Bònn
}

(Eingegangen am 11. April/26. Juli 1972)

\begin{abstract}
Es wurde die Wirkung von Heparin in vitro auf die Reninaktivität im Plasma und im Serum des Menșchen unter verschiedenen Bedingungen untersucht. Bereits geringe Mengen von Heparin hemmten im Plasma die Freisetzung von Angiotensin; die Hemmung war von der Heparinkonzentration abhängig. Wurde Heparin dem Serum vor der Dialyse zugesetzt, so war die Hemmung geringer als bei Zusatz nach der Dialyse. Diese Befunde sprechen gegen eine ausschließliche Kompetition zwischen Reninsubstrat und Heparin. Aufgrund der vorliegenden Ergebnisse ist die Bestimmung der Reninaktivität im Heparin-Plasma abzulehnen.
\end{abstract}

\section{In vitro activity of beparin on the renin activity in plasma}

The effect of heparin in vitro on the renin activity in human plasma and serum was examined under various conditions. Even small amounts of heparin in the plasma inhibited the liberation of angiotensin, and the inhibition was dependent on the heparin concentration. If heparin was added to the serum before the dialysis, the inhibition was less than when the heparin was added after dialysis. This finding weighs against an exclusive competition between the renin substrate and heparin. On the basis of the results given here, the determination of renin activity in heparinized plasma should be avoided.

Während der letzten Jahre haben mehrere Autoren über die Wirkung von Heparin auf das Renin-Angiotensin-Aldosteron-System berichtet. So fanden SchLATMANN et al. (1) nach Gabe von Heparin und Heparinoiden eine verminderte Ausscheidung von Aldosteron im Urin; als Ursache vermuteten sie eine Blockierung des Renin-Angiotensin-Systems. Diese Annahme wird durch die Untersuchungen von JAQUES et al. (2) unterstützt, aus denen hervorgeht, daß sich Heparin als Säure mit Angiotensin II zu einem schwer dialysierbaren Komplex verbindet. ConN et al. (3) sind der Ansicht, daß die erniedrigte Aldosteronausscheidung nach Verabreichung von Heparin auf eine Hemmung der Biosynthese von Aldosteron in der Nebennierenrinde zurückzuführen ist; auch MAJOOR (4) kommt anhand neuerer Untersuchungen zu dem gleichen Schluß.

SEALEY et al. (5) beobachteten in vitro eine Hemmung der Freisetzung von Angiotensin durch Heparin (5-1900 Einheiten/ml Blut), die umgekehrt proportional zur Konzentration des Reninsubstrats im Plasma war. Die Autoren erklären ihren Befund mit einer reversiblen (kompetitiven) Hemmung zwischen Reninsubstrat und Heparin. Ähnlich wiesen auch KaNeko et al. (6) eine verminderte Angiotensinfreisetzung in vitro bei Heparinkonzentrationen zwischen 100 und 400 Einheiten/ml Plasma nach; bei Konzentrationen unter 40 Einheiten/ml war die Hemmung jedoch nicht signifikant. Möglicherweise besteht ein Zusammenhang mit der klinischen Beobachtung, daß nach Verabreichung von Heparin über einen längeren Zeitraum der Blutdruck absinkt (7).

Bei vielen Methoden zur Bestimmung der Reninaktivität (vgl. 1. c. (8-11)) wird heparinisiertes Plasma verwendet. Bereits in früheren Untersuchungen hatten sich Hinweise dafür ergeben, daß die Menge der einge- setzten Heparin-Präparation (Liquemin) eine kritische Größe bei der Bestimmung von Renin darstellt (12). Aus diesem Grund wurde in der vorliegenden Arbeit die Wirkung von Heparin auf die Reninaktivität des menschlichen Plasmas in vitro eingehend untersucht. Es zeigte sich, daß Heparin in der Tat einen deutlichen Einfluß auf die Aktivität von Renin ausübt.

\section{Methodik}

Prinzip der Methode zur Bestimmung der Reninaktivität im Plasma und in Serum

Die Reninaktivität wurde.nach der bereits früher keschriebenen Methode (12) bestimmt.

Als Reninsubstrat diente vorbehandeltes Citrat-Plasma nephrektomierter Katzen. Durch Dialysen gegen EDTA-haltige Puffer wurden die Angiotensinasen bei niedrigen pH-Werten (3,3 bzw. $3,9)$ in den zu untersuchenden Plasma- und Serumproben sowie in der Reninsubstrat-Lösung inaktiviert. Die Inkubatiơn von $0,5 \mathrm{ml}$ Plasma oder $0,5 \mathrm{ml}$ Serum mit $0,2 \mathrm{ml}$ ReninsubstratLösung wurde bei $\mathrm{pH} 7,5$ durchgeführt. Das während der 20 stdg. Inkubation entstandene Angiotensin II wurde im Rattenblutdruckversuch in Form eines „Bracket Assay“ gemessen. Wegen des geringeren Arbeitsaufwandes wurde das zur Fällung verwendete Äthanol nicht am Rotationsverdampfer, sondern unter Stickstoff (nachgereinigt) bei $37^{\circ} \mathrm{im}$ Wasserbad eingedampft.

\section{Enzym-Einbeit}

Eine Renin-Einheit (R. E.) ist die Reninaktivität in 0,5 ml Plasma bzw. Serum, die unter Zusatz von $0,2 \mathrm{ml}$ Reninsubstrat-Lösung (Katzenplasma) während einer 20stdg. Inkubation bei $37^{\circ}$ eine vasopressorische Aktivität freisetzt, welche der von $1 \mathrm{ng}$ Asparaginyl-Angiotensin II (Hypertensin CIBA) entspricht.

1) Enzym: Renin (EC 3.4.4.15).

2) Teil der Dissertation H. LIndsraedr, Medizinische Fakultät der Universität Bonn, 1972.

3) Auszugsweise vorgetragen von H. KaulHausen auf dem Congressus Biochimiae Clinicae in Prag, 14.-18. September 1971; vgl. Abstracta, S. 190. 


\section{W Walter de Gruyter Berlin.New York}

\section{Günther Kraft Josef Fischer}

\section{Indikation von Titrationen}

Okłav. XII, 305 Seiten. Mit 124 Abbildungen. 1972. Plastik flexibel DM 58, - ISBN 3110016257 (Arbeitsmethoden der modernen Naturwissenschaft herausgegeben von Prof. Dr. Kurt Fischbeck)

Titrationsverfahren stehen aus den verschiedensten Gründen unter den chemischen Analysenverfahren im Vordergrund. Eine Titration kann aber nur so genau ausgeführt werden, wie es die Indikation ihres Endpunktes ist.

Dieser entscheidenden Frage ist das Buch gewidmet, das als erstes deutschsprachiges seiner Art den Gesamtkomplex der Indikation von Titrationen behandelt.

\section{(TNOW}

\section{Digitale pH I mV-Messung pH Digi 510}

- Bereich pH 0,00-14,00/ $\pm 1999 \mathrm{mV}$

- Genauigkeit $\pm 0,01 \mathrm{pH} / \pm 1 \mathrm{mV}$

- irrtumsfreie Ablesung

- angemessener Preis

Temp. Kompensation manuell oder automatisch, Schreiberausgang, Messung aller Potentiale, auch ionensensitiv.

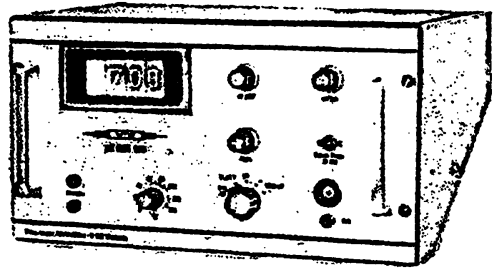

Fordern Sie Prospekte über unser Gesamtprogramm an! Bei Ihrem Fachhändler oder direkt bei uns!
WissenschafillichTechnische Werksä̈tten GmbH Dih hab.K.Slevogt · 812 Weilheim · Tel.(0881) 2638/2784

Buros:

43 Essen K.Akemann, Lönsberg 22, Ruf (0 21 41) 510019

7401 Entringen/Tubingein W. Bohn, Uhlandstrabe 7, Ruf (07 12 02) 566 58 Hagen H. Ducksteln, HestertstraBe 64, Ruf $(02331) 45857$

635 Bad Nauhoim H. Ballauff, Frankfurter Straße 39, Ruf (0 60 32) 4860

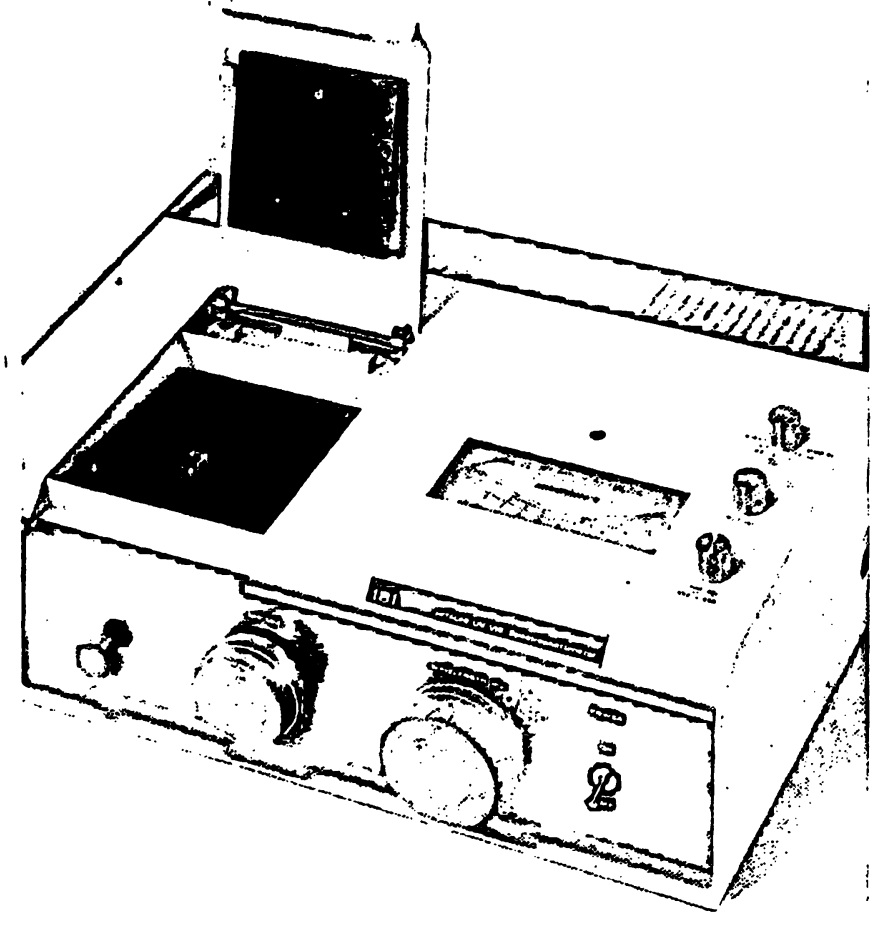

HitachiSpektralphotometer 181

Leistungsfähiges Einstrahl-Spektralphotometer mit hochwertigem Gittermonochromator 1440 Striche pro $\mathrm{mm}$. Spektralbereich: $200 \mathrm{~nm}$ bis $900 \mathrm{~nm}$, Wellenlängengenauigkeit: $> \pm 0,5 \mathrm{~nm}$. Bandbreite: $2 \mathrm{~nm}$. Lineare Anzeige von Transmission und Extinktion in 4 Bereichen: $0-1,0.5-1.5,1-2,0-0.1 \mathrm{E}$. Mit Wolfram- und Deuteriumlampe und eingebautem 4-Küvettenwechsler.

Alleinvertretung für Deutschland:

\section{Colora Messtechnik GmbH}

7073 Lorch/Württ. 1, Postfach 5 T (07172) 60 41, FS 07-248 886

Technische Büros (Verkauf und Kundendienst): 1000 Berlin 30, Ansbacher Straße 17-19, T 244090 2000 Hamburg 19, Osterstraße 63, T 4911034 , FS 02-12 947 3000 Hannover, An der Tiefenriede 45, T 884500 4000 Düsseldorf 1, Kronprinzenstr. 62, T 320164 , FS 08-587 253 6000 Frankfurt a.M., Röderbergweg 4-6, T 446031 , FS 04-11 216 8000 München 19, Dachauer Straße 175, T 193858

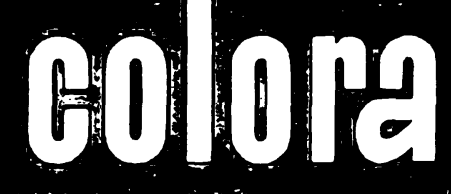


Clinical

\section{Biochemistry}

\section{Principles and Methods}

\section{Edited by H.-CH. CURTIUS}

Medizinisch-Chemische Abteilung der Universitäts-Kinderklinik, Zürich

\section{and}

MARC ROTH

Laboratoire Central

Hopital Cantonal universitaire, Geneve

61 authors from 11 different countries have contributed to this book

which presents many of the techniques of interest to clinical chemists and clinical biochemists.

Current procedures are critically discussed, and special emphasis is given to new methods likely to become important in the coming years. A number of techniques are given in detail, and the others are presented with the appropriate references.

The book contains numerous tables and illustration, and an extensive index permits ready access to specific items.

Approx. 900 pages with many graphs Size: $17 \times 24 \mathrm{~cm}$

Approx. DM 175, - / \$55.50

Prospective date of publication summer 1973

\section{Contents}

\section{General Methodology}

I. Preparation of Samples (M. Roth and H.-Ch. Curtius) II. Methods of Separation Chromatography: Thin-Layer (H. K. Mangöld) - Gel (H. Determann) lon Exchange ( $H$. Determann) Gas-Liquid Chromatography and its Combination with other Analytical Techniques (H.-Ch. Curtius and J. A. Völlmin).

Electrophoresis: Membrane, incl. Immunoelectrophoresis, Gel (Agar, Starch, Polyacrylamide), Thin-Layer, High Voltage and Electro Focussing (J. Jákó and W. Hitzig).

Ultracentrifugation $(H$. Sund and F. Hucho). - Dialysis and Ultrafiltration (T. P. King). - Extraction by Adsorption (A. Niederwieser).

\section{Methods of Analysis}

Photometry: Absorption and Fluorimetry (M. Roth) - Flame Photometry (J. Frei) Atomic Absorption ( $\mathrm{H}$. Brandenberger).Isotope Techniques: Principles and Applications (H. J. Degenhart) Activation Analysis (D. Comar) Radioimmunoassays (J.-P. Felber) Protein-Binding Methods (A. Vermeulen). Mass Spectrometry (J. A. Völlmin). Electrochemical Methods (J. Bierens de Haan) - Ion-Selective Electrodes (J. T. Clerc, E. Pretsch). -

Calorimetric Methods (K. Levin). Enzymatic Analysis'(M. Roth and J.-P. Felber). - Automation and Data Processing (J. Bierens de Haan) including GeMSAEC (N. G. Anderson). Ultramicro Techniques (M. Roth). Statistics (Th.Marthaler).-Quality Control and Normal Values (M. J. R. Healy and F. L. Mitchell).

\section{Detailed Procedures According to Groups of Substances}

IV. Hormones

Peptide Hormones (J.-P. Felber) Function Tests (R. IIlig). - Steroid Hormones: Androgens, Progesterone and Metabolites, Corticosteroids (J.A. Völlmin, H.-Ch. Curtius, H. J. Degenhart and A. Vermeulen) - Estrogens ( $H$. Brever and L. Nocke-Finck) - Aldosterone (A. Aakvaag) - Function Tests (M. Zachmann). - Biologically Active Amines (C. Bohuon). - Thyroid Hormones: Protein-bound lodine (A. Uettwiler) Application of Radioactive lodine in Diagnosis and Treatment of Thyroid Diseases (W. D. Reitsma and M. G. Woldring).

V. Bile Acids (D. Mayer).

\section{Carbohydrates and Related} Compounds

Gas-Liquid Chromatography of Carbohydrates (W. W. Wells). - Glucose, Galactose, Fructose, Inulin and Ketone Bodies in Blood and Urine (E. Hultman). - Glycosaminoglycans

(H. Greiling).

VII. Vitamins

Vitamin A (G. B. Brubacher and J. P. Vuilleumier) - Vitamin $B_{12}$ (U. G. Woldring and A. K. van Zanten) Vitamin $C$ (G. B. Brubacher and J. P. Vuilleumier) - Vitamin D (E. Kodicek and D. E. M. Loiwson). VIII. Lipids (H. K. Mangold)

IX. Amino Acids (Th. Gerritsen and A. Niederwieser) - Fluorimetric Assay of Amino Acids (M. Roth).

$X$. Other Nitrogenous Compounds (G. Ceriotti).

XI. Enzymes

in Plasma (M. Roth, C. Bohuon, J. King and G. Ceriotti) - in Erythrocytes

(W. Schröter) - in Leuccocyłes (J. Frei) Glycogen and Enzymes of Glycogen Metabolism (F. Huijing) - Enzymes of Fructose and Galactose Metabolism, Galactose-I-Phosphate (R. Gitzelmann) in Pancreatic and Duodenal Juice and in Feces (B. Borgström) -

in Intestinal Mucosa (S. Auricchio and A. Rubino) - Defects in Lipidoses and and their Prenatal Detection (R. O. Brady) - UDP-Glucuronyl-Transferase

(J. Frei) - Survey of Enzyme Assay Related Ito Inborn Errors of - Metabolism (R. Gitzelmann, in cooperation with Th. Gerritsen, H. J. Degenhart, M. Roth and others).

XII. Hemoglobins, Porphyrins and Related Compounds: Heme Proteins (K. Winterhalter) - Porphyrins and Related Compounds (M. Doss) Bilirubin and other Bile Pigments (M. Roth).

XIII. Organic Acids in Urine Aromatic Acids (H.-Ch. Curtius, J. A. Völlmin and H. J. Degenhart) Acids of the Tricarboxylic Acid Cycle (L. Kesner) - $\alpha$-Keto Carboxylic Acids (H.-Ch. Curtius) - Other Organic Acids (H. J. Degenhart).

XIV. Toxic Substances and Drugs (H. Brandenberger)

XV. Proteins (W. Hitzig and J. Jákó).

XVI. Tolerance Tests and Clearance Investigations (E. Lèumann).

XVII. Inorganic Substances Cations (G. Ceriotti) - Añions (G. Ceriotti) - Other Metals including Heavy Metals ( $\mathrm{H}$. Brandenberger).

XVIII. Acid-Base Bálähce and Gas Analysis of Respiratory Air and Blood (R. Rispens and W. G. Zijistra) Mass Spectrometry of Blood and Rèspiratión Gases (A. M. Lawson) 


\section{Versuchspersonen}

Die Untersuchungen wurden an drei Frauen (Alter 18-26 Jahre) und sieben Männern (Alter 24-27 Jahre) vorgenommen. Alle Versuchspersonen waren frei von erkennbaren Krankheiten. Dic Frauen erhielten weder orale Contrazeptiva noch andere Hormonpräparate; Schwangerschaften konnten ausgeschlossen werden.

Heparin-Versuche

Um den Einfluß von Heparin (Liquemin 5000, Hoffmann-La Roche AG, Grenzach/Baden) auf die Angiotensinbildung in vitro zu untersuchen, wurde die Reninaktivität sowohl im Plasma als auch im Serum bei Heparinkonzentrationen zwischen 28 und 330 USP-E./ml bestimmt ( $1 \mu \mathrm{l}$ Liquemin 5000 entspricht 5 USP-E. Heparin). Plasma und Serum stammten bei allen Versuchspersonen aus der gleichen Blutprobe; in allen Versuchen wurde der Hämatokrit-Wert bestimmt. Da Heparin nach der Zentrifugation im Plasmaanteil erscheint, konnten mit Hilfe der Hämatokrit-Werte die Heparinkonzentrationen bestimmt werden. Das Heparin wurde mit einer Agla-Spritze (Micrometer Syringe Outfit, Burroughs Wellcome, London) abgemessen; durch vorsichtiges Schütteln der Blut- bzw. Serumproben wurde eine vollständige Durchmischung erreicht. Den Serumproben wurde Heparin entweder vor oder nach der Dialyse zugesetzt.

\section{Ergebnisse}

\section{Einfluß $\beta$ von Heparin auf die Angiotensinbildung in vitro}

Die Reninaktivität war in den heparinfreien Serumproben am höchsten (Tab. 1). Eine deutlich niedrigere Reninaktivität, d. h. eine geringere Bildung von Angiotensin wurde im Plasma festgestellt, wenn sofort nach der Blutentnahme Heparin zugesetzt worden war. Die Hemmung der Angiotensinfreisetzung war hochsignifikant $(p<0,001)$ und konzentrationsabhängig: Bei Zusatz von nur 30 USP-E. Heparin/ml Plasma betrug die Hemmung im Mittel $40-45 \%$; im Bereich von 60-90 USP-E. Heparin $/ \mathrm{ml}$ war sie geringer und nahm dann bei Konzentrationen zwischen 90 und 300 USP-E. Heparin/ml Plasma wieder zu. Der Einfluß von Heparin auf die Plasmareninaktivität bei 10 Normalpersonen ist in Abbildung 1 graphisch dargestellt; dabei wurde die Hemmung, ausgedrückt in $\%$ der Reninaktivität im Serum, gegen steigende Heparin-

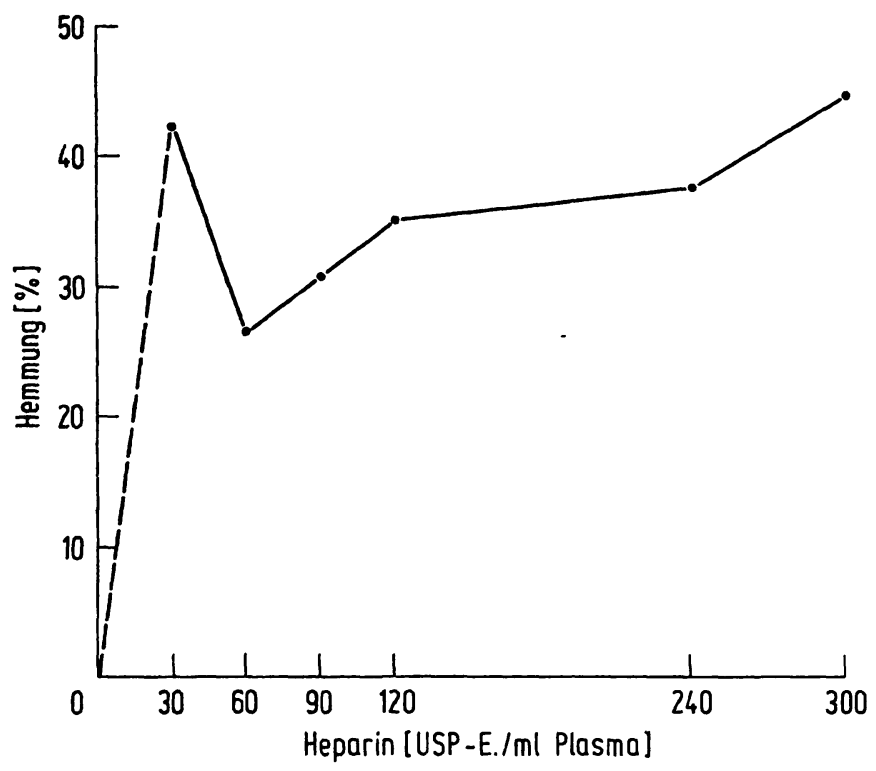

Abb. 1

Hemmung der Reninaktivität im Plasma in Prozent durch steigende Konzentrationen von Heparin; die Werte sind auf die Reninaktivität im heparinfreien Serum bezogen (keine Hemmung). Die Bestimmung der Reninaktivität erfolgte durch Messung des freigesetzten AngioMittelwerte aus den Bestimmungen bei 10 Versuchspersonen

konzentrationen (30-300 USP-E./ml Plasma) aufgetragen.

Auch wenn vor der Dialyse Heparin den Serumproben zugefügt wurde (Tab. 1), ließ sich eine signifikante Hemmung der Angiotensinfreisetzung nachweisen; sie betrug im Mittel $27 \%$ bei Heparinkonzentrationen von 60 und 90 USP-E. Heparin/ml Serum. Erfolgte der Zusatz von Heparin (30-120 USP-E./ml) zu den Serumproben nach der Dialyse (Tab. 1), so war die Reninaktivität gegenüber derjenigen im heparinfreien Serum nur geringfügig verändert; allerdings schienen auch in diesem Fall die absoluten Werte von der jeweiligen Heparinkonzentration in der oben beschriebenen Weise abhängig zu sein.

Tab. 1

Wirkung verschiedener Heparinkonzentrationen auf die Reninaktivität in vitro in Seren und Plasmen männlicher und weiblicher Versuchspersonen. Die Bestimmung der Reninaktivität erfolgte durch Messung der Angiotensinfreisetzung; Einzelheiten vgl. Methodik. Hkt = Hämatokrit

\begin{tabular}{|c|c|c|c|c|c|c|c|c|c|c|c|c|c|c|c|c|}
\hline \multirow{3}{*}{$\begin{array}{l}\text { Ver- } \\
\text { suchs- } \\
\text { person }\end{array}$} & \multirow{3}{*}{$\begin{array}{c}\text { Ge- } \\
\text { schl. }\end{array}$} & \multirow{3}{*}{ Alter } & \multirow{3}{*}{ Hikt } & \multirow{3}{*}{$\begin{array}{l}0 \\
\text { Se }\end{array}$} & \multirow{3}{*}{$\begin{array}{c}6,6 \\
\text { im vor }\end{array}$} & \multirow{3}{*}{$\begin{array}{l}10,0 \\
\text { Dialyse }\end{array}$} & \multicolumn{3}{|c|}{ Zusatz von Heparin } & \multirow{2}{*}{$\begin{array}{l}\left(\frac{10}{13,3}\right. \\
13\end{array}$} & \multirow{2}{*}{$\frac{-\mathrm{Hkt}}{100} \underset{3,3}{ }$} & \multirow{2}{*}{\multicolumn{2}{|c|}{$\left.\underbrace{\mathrm{ml} \text { Plasma }}_{6,6}\right|_{10,0} ^{-1}]$}} & \multirow[b]{2}{*}{13,3} & \multirow{3}{*}{26,6} & \multirow{3}{*}{33,3} \\
\hline & & & & & & & 3,3 & 6,6 & 10,0 & & & & & & & \\
\hline & & & & & & & \multicolumn{5}{|c|}{$\begin{array}{l}\text { Serum nach Dialyse } \\
\text { Renin-Aktivität [R. E.] }\end{array}$} & \multicolumn{3}{|c|}{ Plasma } & & \\
\hline P. B. & $\sigma^{\prime \prime}$ & 25 & 45 & 22 & 18 & - & - & 17,5 & 23,5 & 21 & 8 & 20 & - & 16 & 13 & 12 \\
\hline A. $\mathbf{L}$. & 우 & 26 & 42 & 33 & 28 & 28 & 31 & 32 & 38 & 36 & 24 & 26,5 & 26,5 & 25 & 23 & 22 \\
\hline G. S. & o & 18 & .45 & 20 & 9 & 10 & 17 & 17 & 19 & 17 & 12 & 12 & 10 & 8 & 7 & 7 \\
\hline E. G. & $0^{\prime \prime}$ & 26 & 46 & 34 & 24 & 25 & 28 & 31 & 30 & 29 & 12 & 22 & 21,5 & 21 & 18 & 14 \\
\hline E. G. & 우 & 18 & 44 & 24 & 18 & 19 & 25 & 28,5 & 25,5 & 23,5 & 12 & 17 & 20 & 18 & 17 & 14 \\
\hline W. G. & $0^{+}$ & 26 & 47 & 36 & 25 & 26 & 36 & 42 & 43 & 40 & 19 & 21 & 26 & 23 & 21 & 18 \\
\hline W. N. & $\sigma^{\circ}$ & 24 & 43 & 18 & 12 & 13. & 13 & 14 & 16 & 14 & 11 & 12 & 12 & 10 & 9 & 8 \\
\hline K. K. & $0^{\prime \prime}$ & 26 & 48 & 37 & 22 & 23 & 32 & 37 & 38 & 35 & 26 & 29 & 28 & 27 & 25 & 24 \\
\hline D. $\mathrm{K}$. & $\sigma^{\prime \prime}$ & 27 & 50 & 31 & 25 & 27 & 28 & 30 & 31 & 29 & 25 & 29 & 24 & 23 & 22 & 21 \\
\hline H. S. & $0^{\prime \prime}$ & 26 & 46 & 12 & 10 & 10 & 11 & 12 & 12 & 10 & 6 & 8,5 & 7 & 7 & 5,5 & 5 \\
\hline \multirow{4}{*}{\multicolumn{3}{|c|}{$\begin{array}{l}\text { Mittelwerte } \\
\text { Standardabweichung } \\
\text { Signifikanz }\end{array}$}} & $\bar{x}$ & 26,7 & 19,1 & 20,1 & 24,6 & 26,1 & 27,6 & 25,5 & 15,5 & 19,7 & 19,4 & 17,8 & 16,1 & 14,5 \\
\hline & & & $\mathbf{s}$ & 8,6 & 6,8 & 7,4 & 8,8 & 10,3 & 10,2 & 10,0 & 7,4 & 7,3 & 7,8 & 7,3 & 7,0 & 6,6 \\
\hline & & & $\mathrm{p}_{\mathrm{a}}$ & a & $<0,001$ & $<0,01$ & $<0,02$ & $<0,6$ & $<0,4$ & $<0,2$ & $<0,001$ & $<0,001$ & $<0,001$ & $<0,001$ & $<0,001$ & $<0,001$ \\
\hline & & & $\mathrm{p}_{\mathrm{b}}$ & & & c & & & $<0,005$ & & & & $<0,5$ & & & \\
\hline
\end{tabular}


Tab. 2

Wiederfindung von Angiotensin II (Hypertensin CIBA) nach Inkubation mit Serumproben (Versuch 1 und 2) sowie mit Reninsubstrat-Lösung (Kand 3 . Es wurden jeweils $200 \mathrm{ng}$ Angiotensin 11 in 0,8 ml 0,9proz. NaCl-Lösung aufgenommen und mit 0,2 ml Serum (Katzenplasma; Versuch 3 und 4). Es wurden jeweils $200 \mathrm{ng}$ Angiotensin 11 in $0,8 \mathrm{mi}$ 0,9proz. NaCr-Losum- und Katzenplasma-Proben gegen EDTAbzw. Reninsubstrat-Lösung $20 \mathrm{~h}$ lang inkubiert. Die Angiotensinasen waren durch haltige Puffer bei niedrigem pH-Wert $(3,3 \mathrm{bzw}, 3,9)$ inaktiviert worden

\begin{tabular}{|c|c|c|c|c|c|c|c|}
\hline Versuch & $\begin{array}{c}\text { Angiotensin II } \\
\text { inkubiert } \\
\text { ng }\end{array}$ & $\begin{array}{l}\text { Serumprobe } \\
\mathrm{ml}\end{array}$ & $\begin{array}{c}\text { Reninsubstrat } \\
\text { (Katzenplasma) } \\
\text { ml }\end{array}$ & $\begin{array}{c}0,9 \text { proz. } \mathrm{NaCl} \\
\mathrm{ml}\end{array}$ & $\begin{array}{c}\text { Puffer pH 7,5 } \\
\mathrm{ml}\end{array}$ & $\begin{array}{c}\text { Angiotensin II } \\
\text { nachgewiesen } \\
\text { ng }\end{array}$ & $\begin{array}{c}\text { Angiotensin II } \\
\text { wiedergefunden } \\
\%\end{array}$ \\
\hline $1 a$ & 200 & 0,2 & - & - & - & 170 & 85 \\
\hline b & 200 & - & - & 0,2 & - & 170 I & 85 \\
\hline $2 a$ & 200 & 0,2 & - & - & - & 170 & 85 \\
\hline b & 200 & - & - & 0,2 & - & 170 & 85 \\
\hline $3 a$ & 200 & - & 0,2 & - & - & 170 & 85 \\
\hline b & 200 & - & - & 0,2 & - & 170 & 85 \\
\hline $4 a$ & 200 & - & 0,2 & - & - & 170 & 85 \\
\hline b & 200 & - & - & - & 0,2 & 170 & 85 \\
\hline
\end{tabular}

\section{Inaktivierung der Angiotensinasen}

Die Inaktivierung der im Serum des Menschen sowie in der Reninsubstrat-Lösung (Katzenplasma) vorkommenden Angiotensinasen wurde durch Inkubation von Serum bzw. Reninsubstrat mit jeweils $200 \mathrm{ng}$ Asparaginyl-Angiotensin II (Hypertensin CIBA) überprüft. Es zeigte sich, daß sowohl in den Serumproben als auch in der Reninsubstrat-Lösung die Angiotensinasen vollständig gehemmt wurden (Tab. 2).

\section{Sonstige vasopressorische Substanzen}

Während in der Reninsubstrat-Lösung nach Inkubation mit 0,9proz. $\mathrm{NaCl}$-Lösung oder mit PhosphatPuffer ( $\mathrm{pH} 7,5$ ) keine vasopressorische Aktivität nachgewiesen werden konnte, ergaben die Serumproben deutlich meßbare Leerwerte. Die Versuchsergebnisse wurden dadurch jedoch nicht beeinflußt; auf diesen Punkt ist bereits früher eingegangen worden (13).

\section{Präzision der Metbode zur Bestimmung der Reninaktivität im Serum}

Um die Präzision der Methode beurteilen zu können, wurde eine 10fach-Bestimmung der Reninaktivität im Serum einer männlichen Normalperson vorgenommen. Bei einem Mittelwert von 30,0 R. E. betrug die Standardabweichung (s) $\pm 1,0$; der Variationskoeffizient (VK) war $4 \%$.

\section{Normalwerte der Reninaktivität im Serum}

Bei neun Normalpersonen. (Alter 18-27 Jahre) lag die Reninaktivität im Serum bei Orthostase zwischen 18,0 und 37,0 R. E. Der Mittelwert betrug 28,5 R. E., die Standardabweichung $(s) \pm 7,5$.

\section{Diskussion}

In der vorliegenden Untersuchung konnte ein Einfluß von Heparin (Liquemin) auf die Freisetzung von Angiotensin in vitro nachgewiesen werden. Es zeigte sich, daß die Heparinwirkung konzentrationsabhängig war; das Ausmaß der Hemmung hing davon ab, ob Heparin bereits bei der Blutentnahme, zu Beginn der Dialyse oder erst nach der Dialyse zugesetzt wurde. Mit der von SEALEY et al. (5) vermuteten Kompetition zwischen Reninsubstrat und Heparin kann nur ein Teil unserer Ergebnisse erklärt wẹrden.

1. Wenn der Heparinzusatz zum Vollblut bzw. zum Serum vor Beginn der Dialyse erfolgte, war die Angiotensinfreisetzung während der Inkubation signifikant vermindert; möglicherweise ist dies darauf zurückzuführen, daß Heparin während dẹ Dialyse die aktiven Stellen des Enzyms besẹtzt. Das endogene, im Serum der Versuchspersonen enthaltene Reninsubstrat kann praktisch vernachlässigt werden, da es während der Dialyse bei $\mathrm{pH}$ 3,3 fast vollständig gefällt wird.

2. Im Bereich zwischen 90 und 300 USP-E. Heparin $/ \mathrm{ml}$ Plasma nimmt die Hemmung mit steigenden Heparinkonzentrationen zu. Im Gegensatz zu den Vermutungen von SeAley et al. (5) steht die Beobachtung, daß bei der niedrigen Heparinkonzentration von 30 USP-E./ml Plasma die Hemmung der Angiotensinbildung stärker war als im Bereich ziwischen 60 und 240 USP-E./ml (vgl. Abb. 1).

Wie schon erwähnt, war das Ausmaß der Hemmung davon abhängig, ob Heparin vor der Dialyse oder nach der Dialyse in die Serumproben gegeben wurde. Befand sich Heparin bereits während der Dialyse im Plasma bzw. Serum, so ergab sich eine deutlich geringere Freisetzung von Arigiotensin. Daraus kann gefolgert werden, daß die Hemmung der ReninsubstratRenin-Reaktion dưrch Heparin in vitro hauptsächlich während des Dialysevorganges, d. h. bei niedriger Temperatur $\left(4^{\circ} \mathrm{C}\right)$ einsetzt. Die hier vorgelegten Ergebnisse sprechen gegen die Annahme, daß es sich bei der Wirkung von Heparin auf die Freisetzung von Angiotensin ausschließlich um eine kompetitive Hemmung handelt. Allerdings mụß berücksichtigt werden, $\mathrm{da} ß$ in dem von SEALEY et al. (5) angewandten Verfahren endogenes Reninsubstrat umgesetzt wird, während in den eigenen Untersuchungen exogenes Reninsubstrat Verwendung findet. Im übrigen läßt sich eine Aussage über den Mẹchanismus der Hemmung der Reninaktivität durch Heparin zur Zeit nicht machen. So kann nicht ausgeschlossen werden, $\mathrm{da} B$ die hier eingesetzte Heparin-Präparation. (Liquemin) Begleitstoffe wie z. B. Histamin enthält, welche in die Reaktionen eingreifen, die während der Aufarbeitung und Inkubation der 
Plasmaproben ablaufen. Da zwischen heparinhaltigen Serumproben und Plasmen bei gleichen HeparinKonzentrationen keine statistisch signifikanten Unterschiede in der Angiotensinfreisetzung auftraten (vgl. Tab. 1), ist anzunehmen, da $\beta$ der Gerinnungsvorgang an sich keinen Einfluß auf die Reninaktivität hat.

Aufgrund der oben beschriebenen Beobachtungen ist die Bestimmung der Reninaktivität im Heparin-Plasma abzulehnen, da bereits relativ geringe Konzentrationen von Heparin zu falsch erniedrigten Werten führen; die Unterscheidung zwischen normalen und erniedrigten Reninaktivitäten ist andererseits bei der Diagnostik der „low-renin essential hypertension" (14) von großer Bedeutung. Die genannten Schwierigkeiten lassen sich dadurch umgehen, da $\beta$ man sowohl bei den biologischen als auch bei den radioimmunologischen Verfahren zur Bestimmung der Reninaktivität entweder Serum oder EDTA-Plasma verwendet.

\section{Literatur}

1. Schlatmann, R. J. A. F. M., Jansen, A. P., Prenen, H., VAN DER KORST, J. K. \& MAJOOR, C. L. H. (1964), J. clin. Endocrinol. Metab. 24, 35-47. - 2. JAQues, R., KürTnER, K., BeIN, H. J. \& MEIER, R. (1960), Experientia 16, 147. - 3. ConN, J. W., Rovner, D. R., Cohen, E. L. \& ANDerson, J. E. (1966), J. clin. Endocrinol. Metab. 26, 527-532. - 4. MAjOOR, C. L. H. (1969), Ned. T. Geneesk. 113, 767-771. - 5. Sealey, J. E., Gerten, J. N., Ledingham, J. G. G. \& Laragh, J. H. (1967), J. clin. Endocrinol. Metab. 27, 699-705. - 6. KANEKo, Y., IKEDA, T., TAKEDA, T. \& UEDA, H. (1967), J. clin. Invest. 46, 705-716. 7. Keller, R. (1955), Medizinische I, 492-495. - 8. Brown,
J. J., Davies, D. L., Lever, A. F., Robertson, J. I. S. \& Tree, M. (1964), Biochem. J. 93, 594-600. - 9. SKINNER, S. L. (1967), Circ. Res. 20, 391-402. - 10. Hejmer, O. M. \& Judson, W. E. (1963), Circulation 27, 1050-1060. - 11. Pickens, P. T., Bumpus, F. M., Lloyd, A. M., Smeby, R. R. \& Page, I. H. (1965), Circ. Res. 17, 438-448. - 12. Kauliausen, H., Fillmand, B. \& Breuer, H. (1970), diese Z. 8, 254-258. - 13. Kaulhausen, H., Schmidt, H., Lindstaedt, H. \& Breuer, H. (1972), diese $Z$. 10, 151-155. - 14. Laragh, J. H. (1971), Circulation 44, 971 bis 974 .
Prof. Dr. H. Breuer

Inst. f. Klin. Chemie u. Klin. Biochemie 53 Bonn-Venusberg 